\title{
Development of Learning Tools using Maples for Engineering Mathematics Subject
}

\author{
Norlenda Mohd Noor*, Hanifah Sulaiman, Zuraida Alwadood, Suhaila Abd Halim, \\ Nurul Filzah Syamimi Wahid, Nor Adilah Ab Halim \\ Center for Mathematical Studies, Faculty of Computer and Mathematical Sciences \\ Universiti Teknologi MARA, Malaysia
}

\begin{tabular}{l} 
Article Info \\
\hline Article history: \\
Received Jul 9, 2017 \\
Revised Nov 26, 2017 \\
Accepted Dec 11, 2017 \\
\hline
\end{tabular}

Keywords:

Engineering Calculus Learning Tools Maple

\begin{abstract}
Mathematics is one of the basic and core subject for engineering students. Learning mathematics helps in developing problem solving skills as the subject requires critical thinking. However, many students perceive mathematics as a difficult subject and eventually get poor result for the subject. In the institution under study, there were increases in failure rate for the subject for the past few semesters. Based on a preliminary study, it was found that 55 percent of engineering student claimed that they encountered difficulties in visualizing functions in 3-dimensional space, which is the main content for engineering calculus subject. This fact is very unsatisfactory as engineering students are expected to possess strong mathematical problem solving skills. In light of this, the objective of this research is to develop an interactive teaching and learning tools, so as to assist students in visualizing 3-dimensional space functions. The tool is intended to be used in teaching and learning process in classrooms and it is expected that the students' understanding in the subject could be improved.
\end{abstract}

Copyright () 2018 Institute of Advanced Engineering and Science. All rights reserved.

\section{Corresponding Author:}

Norlenda Mohd Noor,

Center for Mathematical Studies, Faculty of Computer and Mathematical Sciences,

Universiti Teknologi MARA, 40450 Shah Alam Selangor, Malaysia (+603-55435356).

Email: e-mail: norlenda@salam.uitm.edu.my

\section{INTRODUCTION}

Despite of being the prerequisite for engineering courses, a preliminary research has found that many students perceived calculus as a high level of difficulties among any other mathematics courses. An analysis of mathematics results over a number of semesters in the institution under study has shown an alarming rate of failure in the subject. There are varieties of factors that contribute to this failure rate. Class absenteeism is one of the main factor that leads to lack of thorough knowledge of the subject [1]. Furthermore, insufficient practices in working out the problem-solving exercises also contributed to this problem. Based on observation, students easily distracted by surrounding activities and this may contribute to loss of focus and attention. As a result, the basic mathematics skills and knowledge are not absorbed entirely in classrooms [2]. In addition to this, students perceived mathematics as a difficult subject. The difficulties in acquiring the mathematic skills and concepts may deteriorate if the teaching and learning process remain ineffective for the students.

Learning calculus can be such a dry subject with the traditional method of teaching, which involved text book, the board writing and exercise handouts. Records showed that the failure rate for an engineering calculus in one of the public university increases from 25 to 45 percent for the past few semesters. This rate is high since engineering students are expected to possess strong mathematical skills and thinking. From a preliminary survey participated by over 800 engineering students, factors that have contributed to this figure 
include poor mathematics background, problems in memorizing formulas, misunderstood concept and mathematics anxieties.

Nevertheless, with the advancement of technology, learning mathematics can be made interesting and joyful. Since the revolution of computer technology, many researchers have found ways to catch student interest in learning calculus. Many computer software and applications have been developed to help improve student understanding in many subjects. A bulk of mathematics applications software on learning mathematics is available in the market, such as Maple, MATLAB, Mathematica and others. These softwares are continuously upgraded in order to make them more effective and user-friendly. These systems have benefited undergraduates and postgraduates in mathematics, engineering and physics courses by keeping track of the details in complicated manipulations [3].

There are many challenges that teachers or lecturers have to face to ensure the understanding of the students in the subject matter. Among the challenges is the difficulty in teaching different types of students in a classroom. In general, there are two types of student in classroom and these two groups have different performance outcomes [4]. The first type is the mixed-ability group who tend to attribute their mathematics performance to their teacher. The second type is the vocational-and academic-track group who are more likely to blame themselves when they failed to perform well. Other challenge include the exam anxiety, which is also a causative factor that answers why students are not able to successfully complete the course [5].

Nowadays, students are more attracted to study using modern technology. Students can use mathematics software or applications to help them understand the subject better. In a recent survey, it was reported that about 55 percent of engineering students have admitted that they encountered difficulties in visualizing 3-dimensional space function. This problem is closely related to spatial ability. By definition, spatial ability is a capacity for mentally generating, rotating, and transforming visual images. This ability is important for developing expertise in learning and work settings since it is one of the three specific cognitive abilities. Unfortunately, not all students have this particular ability and this weakness has force them to struggle in understanding the topic of 3-dimensional functions. They are not able to solve the given problems if they failed to visualize the physical shape of the solids involved in the question. These functions include sphere, cone, paraboloid or other quadric surfaces. In view to this, it is the intention of this research to introduce a customized computer application to assist their learning process in visualizing the 3-dimensional space functions.

In this modern era, there are ways to help student to improve the understanding of mathematics by means of interactive learning technology. Mathematical software can help students in solving a problem when dealing with complex questions [6]. It may help students to improve their programming skills and prepare them for future, specifically when their future working environment requires them to use programming languages. In addition, these learning tools can also help the student in a simple task, such as plotting 2-dimensional or 3-dimensional functions by using the computer. As an example, by only changing a function parameter, different curve or graphs can easily be plotted. When this practical part has been made easier for them, students will have more time to focus on the fundamental knowledge of the subject. Furthermore, many research have shown that the use of software or any interactive tools have definitely increases the students' interest and understanding on the subject matter $[7,8]$.

As a whole, with these mathematical interactive tools, the learning process can be made interesting and enjoyable, besides improving the students' understanding in the subject matter. Despite these advantages, some of the downsides of these learning tools are due to the cost factor and the connectivity to the cloud server.

The objective of this research is to develop an interactive teaching and learning tools for engineering calculus sub topic. The scope of the sub topic includes, vector field, curl, divergence and basic line integral, under the section of vector calculus. This tool is uploaded into a cloud website to make it easily accessible for any students taking the subject.

The paper is organized as follows: Section 2 presents the Research Method, Section 3 discusses the Results and Analysis; and the last section presents the conclusion of the paper.

\section{RESEARCH METHOD}

This research is divided into four phases, as depicted in Table 1. The first phase involved a preliminary survey to gather information on the students taking the subject. The second phase involved the development of the application on three different topics. Once the application is fully developed and integrated, it will be utilized in classroom teaching and learning process and student will be given a survey question to evaluate the effectiveness. 
Table 1. Summary of the research flow

\begin{tabular}{lll}
\hline Phase & Activities \\
\hline Phase I & $:$ & Preliminary survey \\
Phase II & $:$ & Development of the application on each topic of the subject \\
& & a. Pre-test \\
Phase III & $:$ & b. Test run the application \\
& & c. Post-test \\
Phase IV & $:$ & Analysis
\end{tabular}

\subsection{Phase I}

A preliminary survey was conducted in July 2016, in which 800 engineering students took part in answering a set of questionnaires. These students were selected from four engineering faculties, namely civil, mechanical, and electrical and chemical engineering. They have different background education, in which they came from engineering diploma programs, matriculation studies and science diploma programs. There are almost 80 percent of them managed to obtain at least A grade for their mathematics subject in diploma program.

\subsection{Phase II}

The engineering calculus subject contains three main topics, sequence and series, multiple integration and vector calculus. The main idea is to develop the computer application for these three topics. In this paper however, we focused on the third chapter, that is, vector calculus. The application was developed by using Mathlet from Maple 2016.

As for the beginning, the chosen sub topics for the development under vector calculus are the line integral, the gradient of a function, divergence and curl. Figure 1 shows the front page of MAPLE 2016 software. The Text and Math mode button, Combo Box, Mathematical Expression, Plot container and some of other menus are used to create this Mathlet tool.

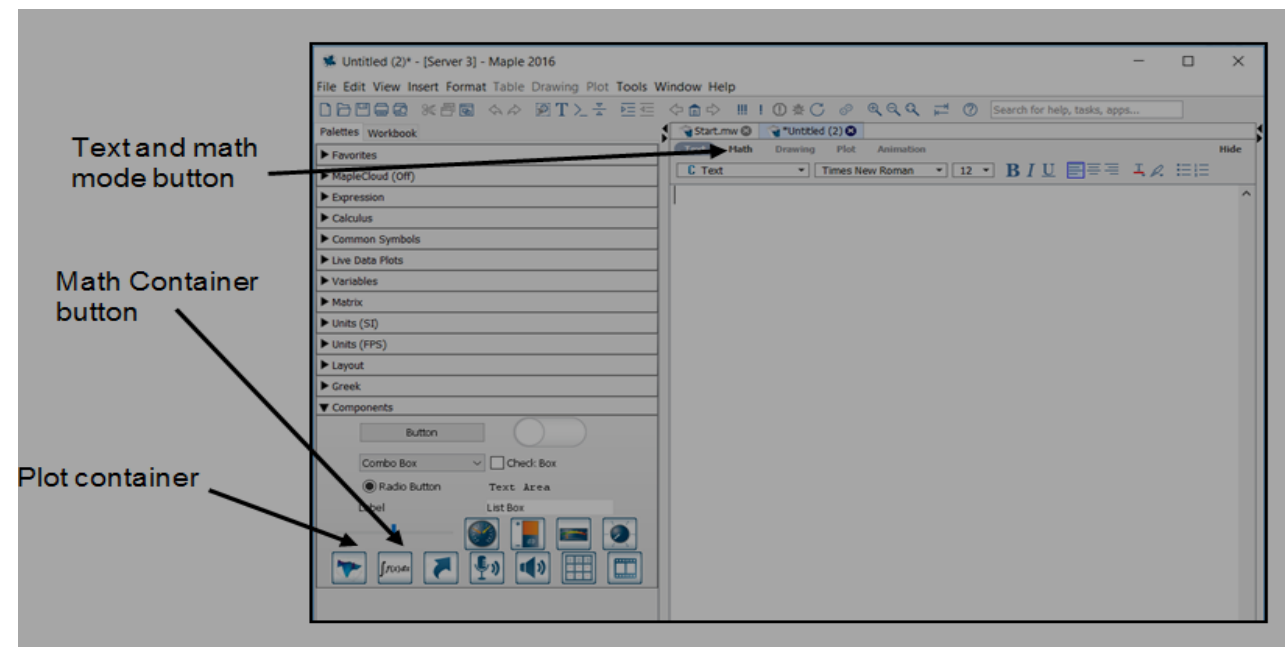

Figure 1. Front Page of Maple 2016

First, the tables for Mathlet are created. Then the button, text, mathematical expression box and also the plot box were added using component palette. For the development of the equation, Do command is used to generate the solution. Others command uses the Maple command and the Edit Click Action is clicked to insert the source code of the sub-topic. Then, the file is saved in any preferred folder. Figure $2 \mathrm{a}$ and Figure $2 \mathrm{~b}$ shows the component properties for the created button. If a button consists of certain conditions that need to be satisfied, Do command is required. 


\begin{tabular}{|c|}
\hline $\mathrm{Ctrl}+\mathrm{X}$ \\
\hline $\mathrm{Ctrl}+\mathrm{C}$ \\
\hline$>$ \\
\hline $\mathrm{Ctrl}+\mathrm{V}$ \\
\hline \\
\hline \\
\hline \\
\hline
\end{tabular}

Figure 2a. Component Properties

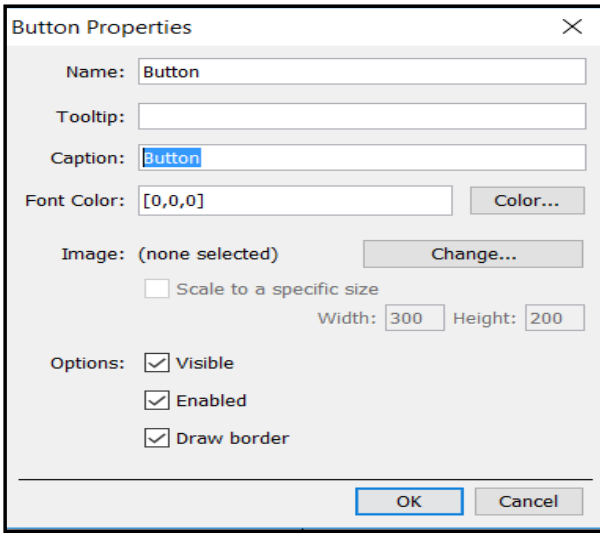

Figure 2a. Windows for creating Buttons

Figure $3 \mathrm{a}$ and Figure $3 \mathrm{~b}$ depicted the process for developing the equations. Do command are being used to generate the solution. Others command used the Maple command. We clicked Edit Click Action to insert the source code of the sub-topic.

\begin{tabular}{ll}
\hline \multicolumn{1}{|r|}{ Cut } & $\mathrm{Ctrl}+\mathrm{X}$ \\
Copy & $\mathrm{Ctrl}+\mathrm{C}$ \\
Copy Special & \\
Paste & $\mathrm{Ctrl}+\mathrm{V}$ \\
\hline Table & \\
Component Properties... \\
Edit Click Action... \\
Create Task
\end{tabular}

Figure 3a. Edit Click Action

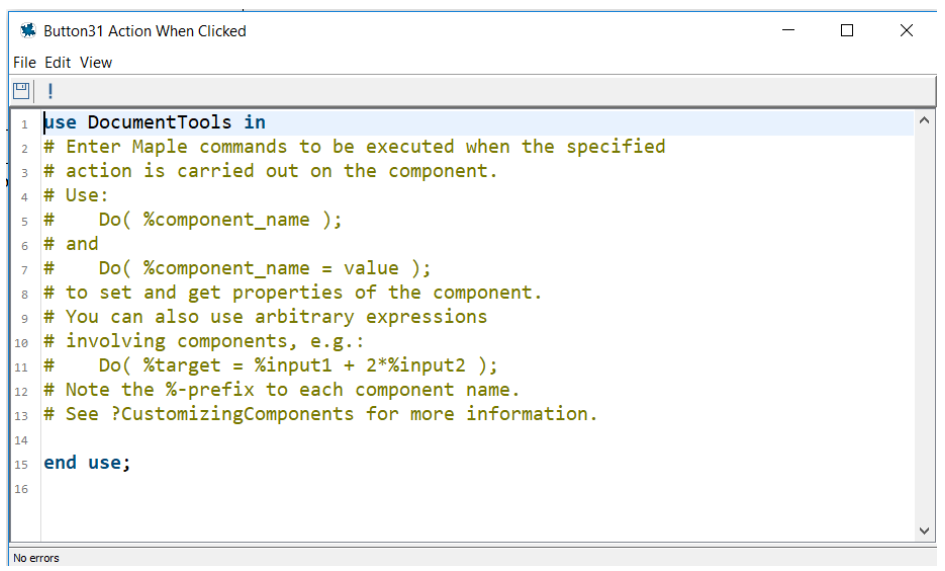

Figure 3b. Window for editing the source code

The interface of the app is discussed in Result and Analysis. Once the other two topics have been fully developed, it will be integrated to one single application to cater the students taking this engineering calculus subject.

\subsection{Phase III and Phase IV}

In this phase, students will be given a set of survey questions regarding the subject. They will be asked to share the experience in learning and understanding the subject with and without the use of the developed tool. A survey will be carried out to evaluate the effectiveness of the new application. The analysis from the survey will be discussed in the future research paper.

\section{RESULT AND ANALYSIS}

The following figures depicted the interface for solving gradient, divergence, curl, line integral and the graph of the vector field that are designed in this tool. Figure 4 shows the interface for solving gradient. A student is required to enter a scalar function in two or three variables in the empty box on the left column. The solution will appear in the right column once they clicked the Solve for Gradient button. The purpose of the second row is to evaluate the gradient at any particular point $(x, y, z)$. To evaluate a different gradient, 
student can click the Reset All button. Figure 5 on the other hand, shows another sample for solving gradient of any function of 3 variables.

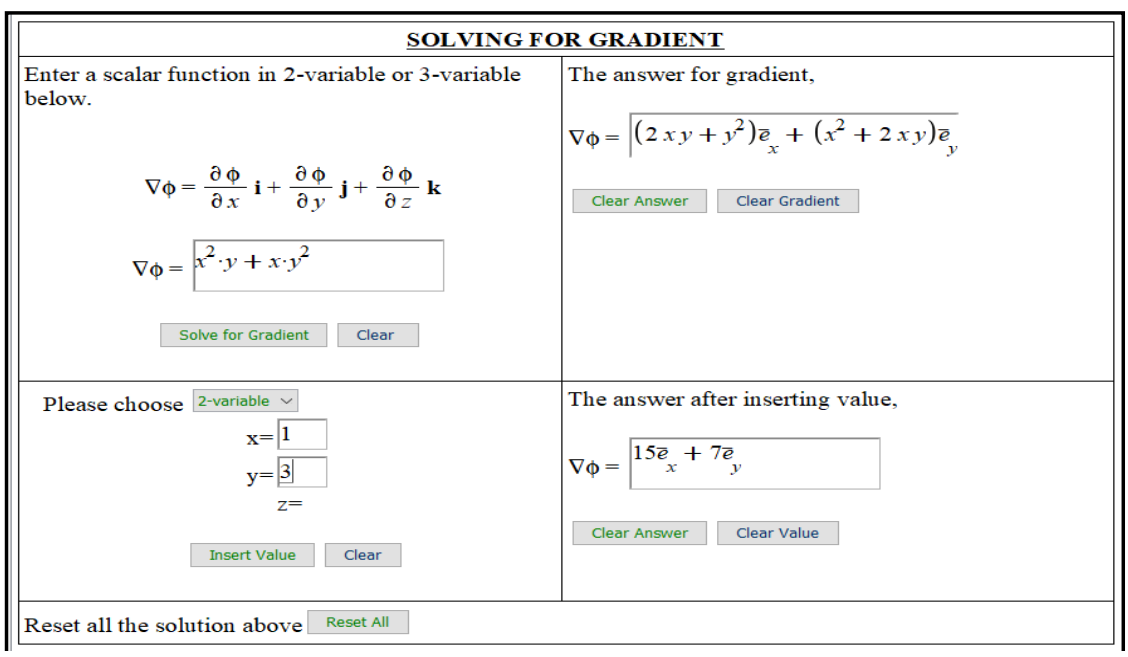

Figure 4. Result for 2-variable Gradient

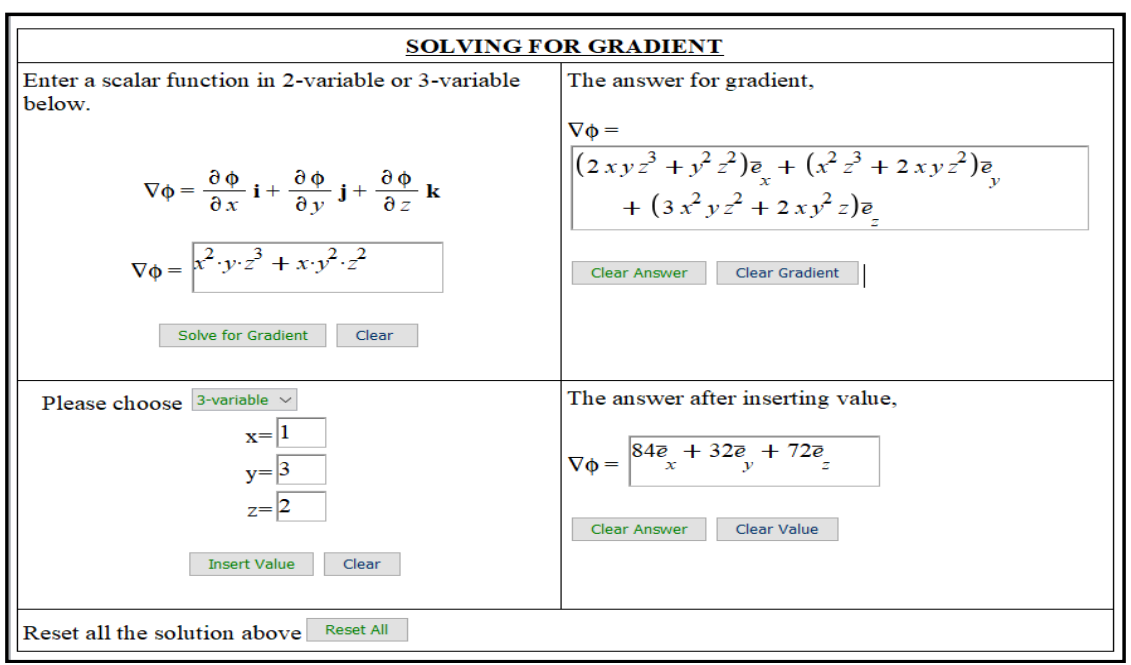

Figure 5. Result for 3-variable Gradient

For solving Divergence and Curl, Combo Box is used to choose either 2-space or 3-space. The 2space will display a zero value at $\mathrm{R}$ box and value $\mathrm{z}$ box. The Divergence value will display incompressible if the result value is zero. If the Divergence displays a positive value, it is compressible and source while negative value means that the vector field is compressible and sink. For Curl, it will show irrotational and conservative if the result appears as zero value. Else, it will be rotational. Figure 6 and 7 shows sample of solving for divergence and curl in 2-space 3-space, respectively.

The graph in Figure 8 displays the direction that is dispersed for vector field $f(x, y)=x^{2} y+x y^{2}$. The range of the graph for $\mathrm{x}$-plane, $\mathrm{y}$-plane and $\mathrm{z}$-plane are -1 to 1 , respectively.

The last interface shown in Figure 9 enables the student to solve the line integral, in which the curve that a particle moves from point $a$ to point $b$ is a straight line. Students are required to enter the component of the vector field, the starting and ending point. Then, solution will appear at the second row on the right box. As shown in Figure 9, student will find that evaluating a line integral or work done by any vector field is very easy, as long as they have the basic knowledge about the line integral itself. And, it is the intention of this research to upgrade the application to different types of curves, such as circle, parabolic and others. 


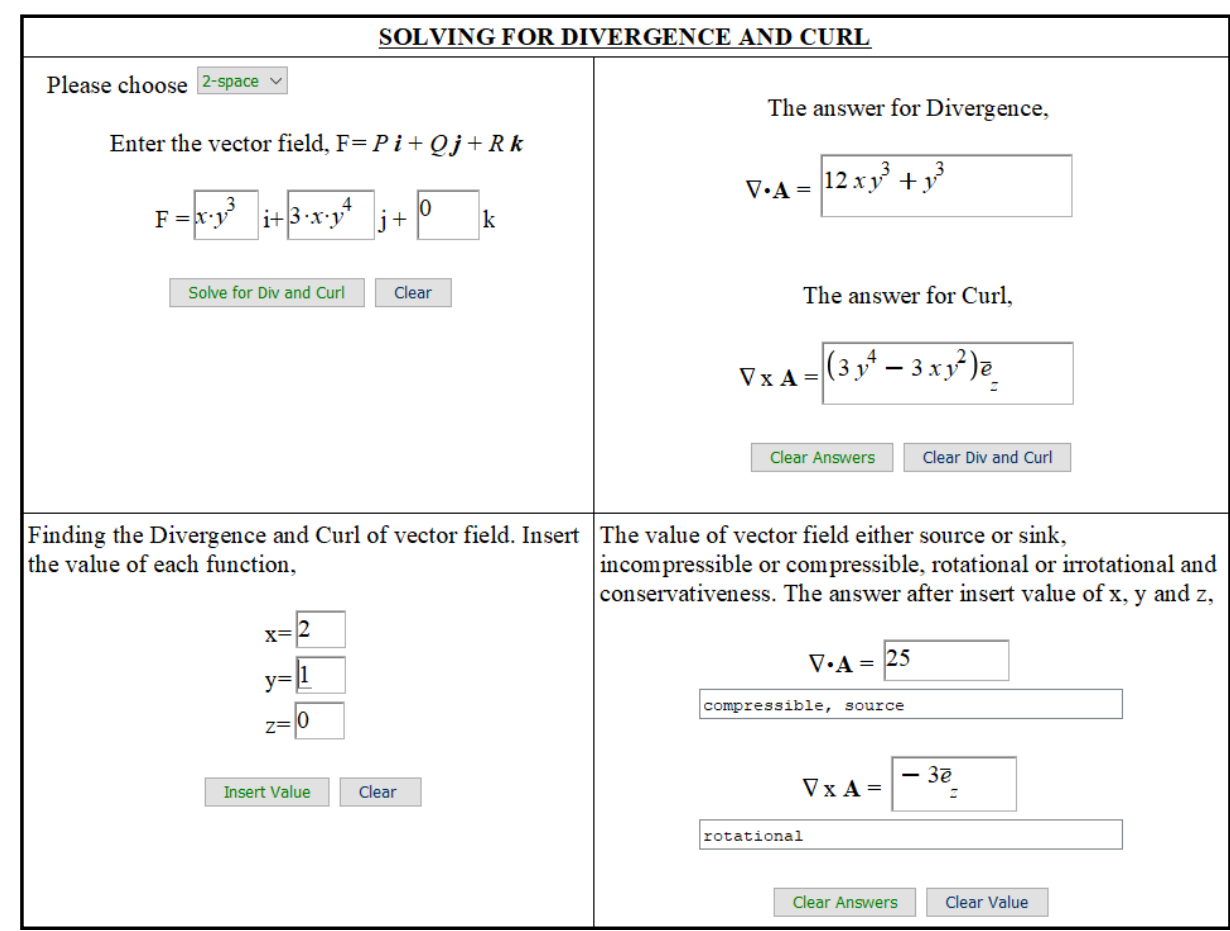

Figure 6. Solving Divergence and Curl for 2-space

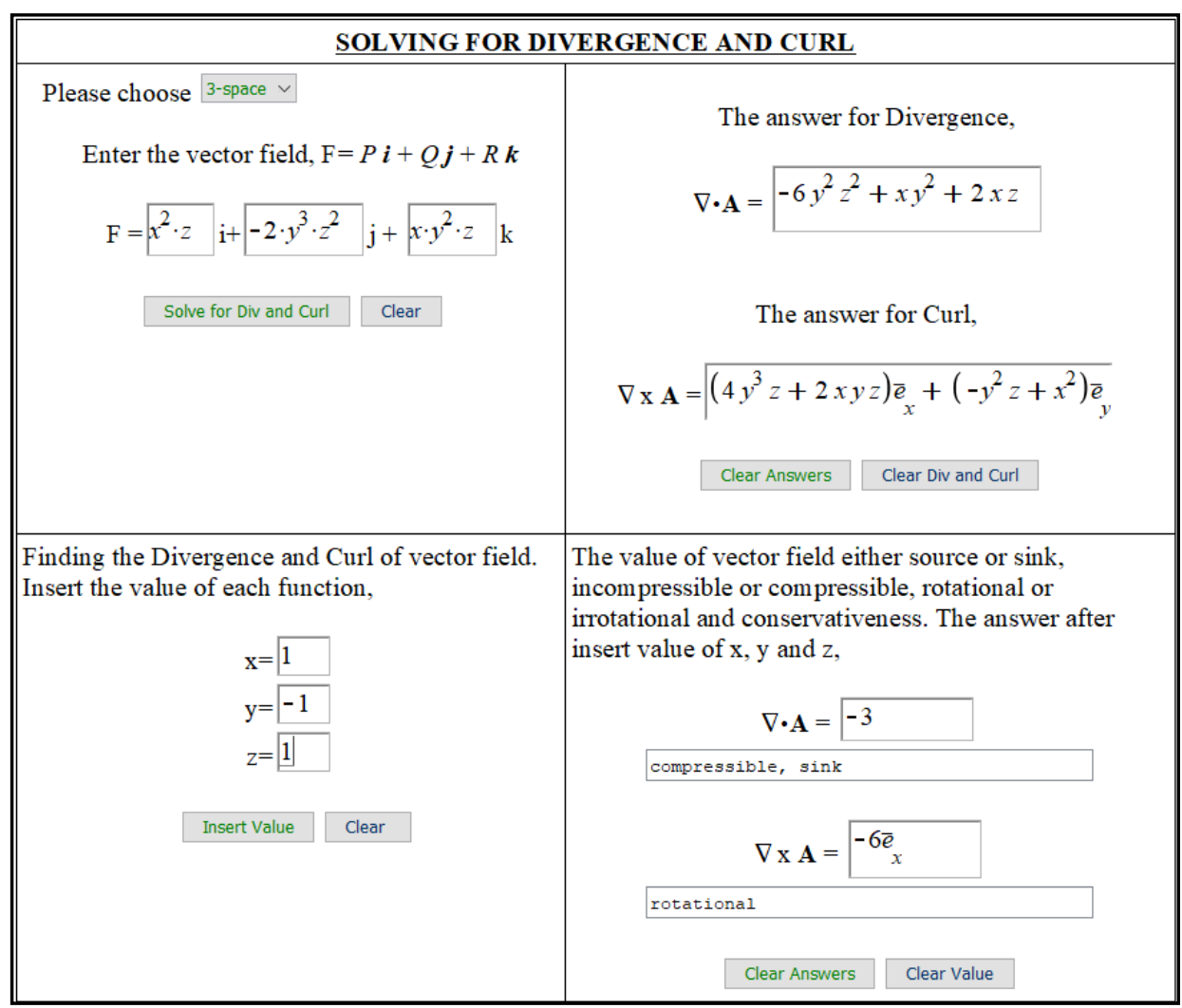

Figure 7. Solving Divergence and Curl for 3-space 


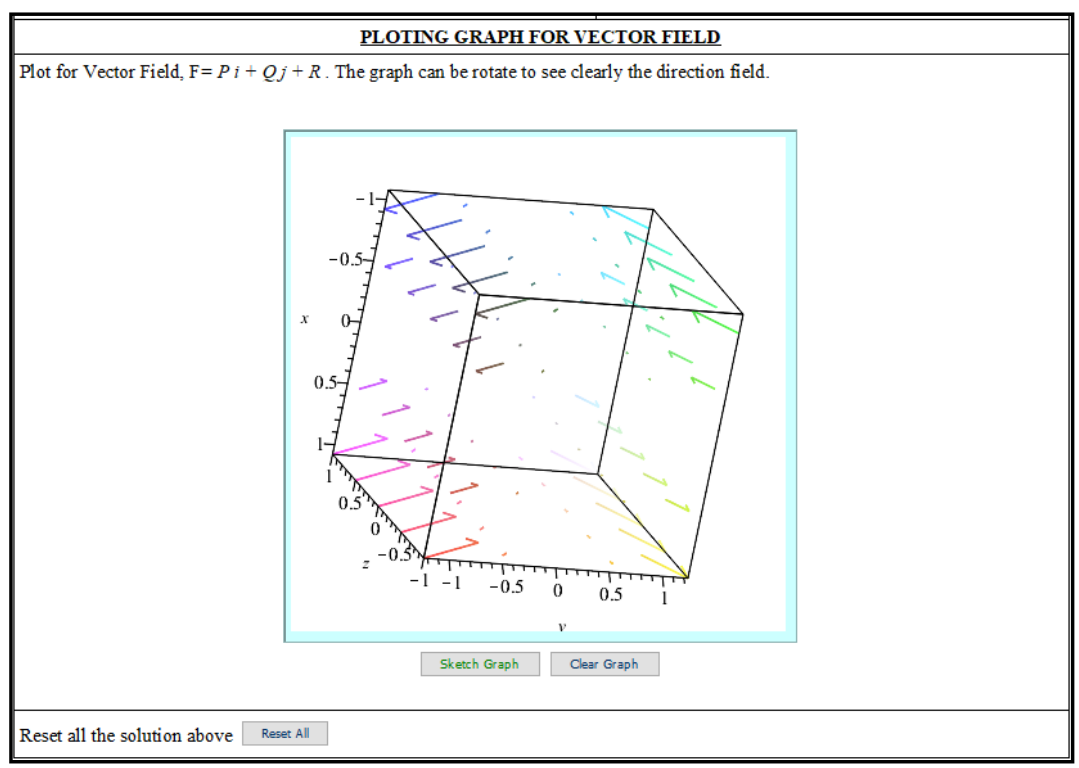

Figure 8. Plotting graph for vector field

$$
\mathrm{W}=\int F \cdot d r=\int_{a}^{b} P d x+Q d y+R d z
$$

Enter the component of $\mathrm{P}$ and $\mathrm{Q}$ below,

$$
\boldsymbol{F}=\sqrt{\left(x^{2}-y\right)} \mathbf{i}+\left(y^{2}+x\right) \quad \mathbf{j}+\mathbf{k}
$$

\section{Clear Component}

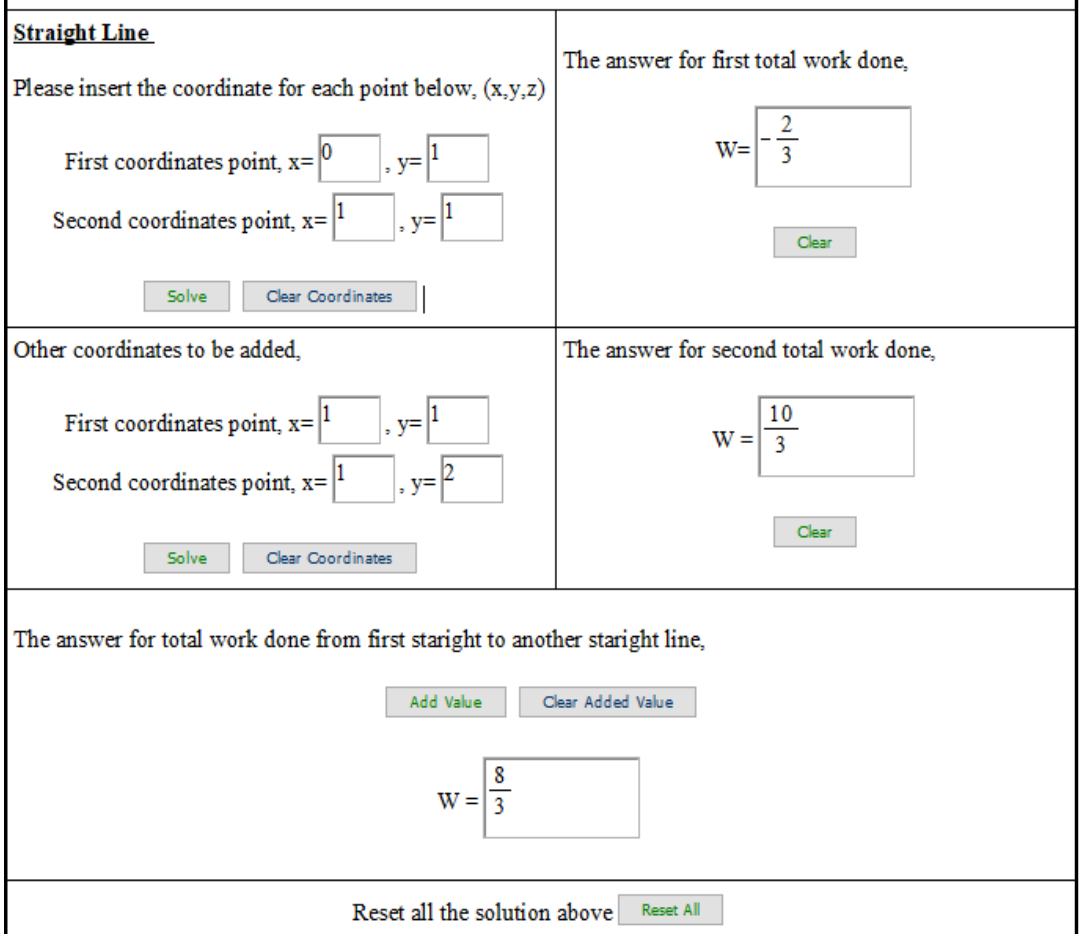

Figure 9. Interface for Solving Line Integral 
This application was uploaded to the Maple Cloud. Students from any part of the world are able to access the application at any time, as long as they are connected to a network. In addition, the students are also able to use this facility at any time convenient to them.

The application needs many more enhancement and improvements series, as it is only an introductory part of a graphical user interface (GUI) development. There are also many other sub topics can to be added in the application, among them are Surface integral, Divergence theorem and Stokes theorem. Different types of surfaces and curves will also be added to cater variety forms of vector calculus problems. Besides that, the content on the other two topics will be developed and these will then be integrated as a single teaching and learning tools for student as well as the lecturers.

In the future project, the application will be tested by users, the student, together with the lecturers. It is anticipated that this application is able to help the student in their class assignment, tutorial and thus deepen their understanding of the subject content.

\section{CONCLUSION}

In conclusion, the teaching and learning tool using Mathlet was successfully developed for vector calculus sub topics which are gradient, divergence, curls and line integrals. The tool can be used in a classroom learning process and it is expected that it is able to improve the students' understanding on the subject content. Furthermore, this tool can also help them with their tutorials and assignments. Further study will be looking at the analysis of the students' performance after the interactive tool is introduced in classroom and this will be followed by the next development of learning tools covering other topics in engineering calculus.

\section{ACKNOWLEDGEMENT}

This research is funded by the Institute of Research Management \& Innovation (IRMI), Universiti Teknologi MARA Malaysia (UiTM) under the ARAS Grant (600-IRMI/DANA5/3/ARAS (0184/2016)). The authors would like to thank the IRMI, UiTM and all lecturers, students, research assistants and other individuals who are either directly or indirectly involved in this project.

\section{REFERENCES}

[1] Prakash AP, Jerlin JE, Fernandes JB. A study on the causes for failures in Mathematics by engineering students using CFRM model. Lect Notes Eng Comput Sci 2014; 1: 29-33.

[2] Berch DB, Mazzocco MMM. Why is Math So Hard for Some Children? The Nature and Origins of Mathematical Learning Difficulties and Disabilities. In: Journal of Developmental \& Behavioral Pediatrics. Pauls H. Brookes Publishing Co., p. 342.

[3] Kilicman A, Hassan MA, Husain SKS. Teaching and learning using mathematics software 'the new challenge'. Procedia - Soc Behav Sci 2010; 8: 613-619.

[4] Effandi Zakaria, Tuan Salwani Salleh. Using Technology in Learning Integral Calculus. Mediterr J Soc Sci 2015; 6: 144-148.

[5] Fuller E, Deshler J, Darrah M, et al. Anxiety and Personality Factors Influencing the Completion Rates of Developmental Mathematics Students To cite this version :

[6] Formaneck SD. Math Software in the Classroom : Pros, Cons and Tips for Implementation. 2013; 14: 11-14.

[7] Gunawan TS, Bahari B, Kartiwi M. Development of educational game for primary school mathematics using microsoft kinect. Indones J Electr Eng Comput Sci 2017; 6: 457-463.

[8] Abdulameer A, Sulaiman M, Aras MSM, et al. GUI Based Control System Analysis using PID Controller for Education. Indones J Electr Eng Comput Sci 2016; 3: 91. 